\title{
Incidence of Postdural Puncture Headache in Patients Undergoing Lower Segment Ceasserian Section
}

\author{
Dr Sanjot Ninave', Dr Pooja Verma ${ }^{2}$ \\ Department of Anaesthesiology, Acharya Vinobha Bhave Rural Hospital, Sawangi, Wardha 442001, India
}

\begin{abstract}
Spinal anesthesia is the most commonly performed anesthesia technique in patients undergoing cesarean sections. Postdural puncture headache (PDPH) is one of the common complications following spinal anesthesia more so in obstetric patients. It is preventable complication, hence a study was undertaken to know the incidence of PDPH in patients undergoing cesarean sections.100 patients belonging to ASA grade I \& II, age group ranging from 20-40 years who are subjected to LSCS were considered for the study. Study was conducted at Acharya Vinoba Bhave Hospital, attached to Jawaharlal Nehru Medical College. Inj Bupivacaine H 0.5\% is injected at L3-L4 level using 23 \& $25 G$ Quincke needle. Result: Only 2 patients out of 100 had complaint of headache. Conclusion: Incidence of postdural puncture headache has been significantly reduced due to use of finer spinal needles.
\end{abstract}

Keywords: Spinal anesthesia, LSCS, Postdural Puncture headache (PDPH), 23 \& 25Gauge Quincke needle

\section{Introduction}

Complications of regional anaesthesia has been recognised from very long time. Fortunately serious complications are rare. Safe, effective practice of neuraxial anaesthesia requires a detailed knowledge of potential complications, their incidence and risk factors associated with their occurrence. PDPH remains the most frequent complication of central neuraxial blockade. It can occur following uncomplicated spinal anesthesia as well as accidental dural puncture in epidural anesthesia.

Postdural puncture headache appears within 1-2 days of dural puncture and may last for several weeks.(1) Every patient does not develop postdural puncture headache (PDPH) after dural puncture. The headache worsens within 30 minutes of assuming the upright position and disappears or improves within 30minutes of resuming recumbent position . The International headache society has defined PDPH as a bilateral headache that develops within 7 days after lumbar puncture and disappears within 14 days.(2) Previously it was believed that the leak of CSF from dural hole is responsible for Postdural puncture headache.

The CSF leakage, compensatory dilatation of cerebral veins, increased brain volume and downward brain sagging with traction of pain sensitive structures within the cranium secondary to loss of CSF has been explained as the cause of PDPH in spinal anaesthesia(3). . PDPH is a self limiting and nonfatal condition, its postural nature prevents the patient from performing routine activity and patient may be anxious and depressed. These patients require psychological support and reassurance with therapeutic measures. Preventive measures like smaller needle size, shape of needles and direction of needle bevel in relation to dural fibers, should always be considered with the hope to decrease the incidence of PDPH.(4)

\section{Aims and Objectives}

1. To find out incidence of PDPH with spinal needle no. $23 G \& 25 G$

2. To find out the associated causes of PDPH

\section{Pathophysiology}

Exact mechanism of PDPH is still not fully understood. Excessive loss of cerebro-spinal fluid (CSF) through dural puncture leads to intracranial hypotension and demonstrable decrease in CSF volume and appears to be the main cause of $\mathrm{PDPH}$ and was first proposed in 1902. Continuous leakage of CSF leads to decreased CSF pressure and volume; the relationship between lower CSF pressure and volume and $\mathrm{PDPH}$ is unclear. (16) CSF is produced at an average rate of $500 \mathrm{ml} /$ day, and approximately $150 \mathrm{ml}$ is circulating at a time around the brain and spinal cord. Body cannot immediately compensate for loss of CSF. Throbbing and orthostatic nature of headache constitutes an important symptom of cerebral vasodilatation and intracranial congestion of blood and supports the hypothesis that the loss of CSF causes compensatory cerebral vasodilatation resulting in PDPH. (17)Rich innervations of adrenergic, cholinergic, and peptidergic fibers in the duramater may play a role in the management of PDPH with epidural blood patch but it require further researches to know exact mechanism of PDPH.

\section{History}

PDPH was first described by August Bier in 1898. In August 1998, Karl August Bier(7), a German surgeon, injected cocaine 10- $15 \mathrm{mg}$ into the subarachnoid space of seven patients including himself and his assistant. Bier and his assistant described headache as high pressure in the head accompanied by light dizziness which disappeared on lying supine and reappeared in upright position. 


\section{International Journal of Science and Research (IJSR) \\ ISSN (Online): 2319-7064 \\ Index Copernicus Value (2015): 78.96 | Impact Factor (2015): 6.391}

In 1951, Whitacre and Hart (8) developed the pencil-point needle, based on the observations of Greene(9) in 1926. Developments in needle design since that time have led to a significant reduction in the incidence of post-dural puncture headache.

\section{Incidence}

The incidence of post dural puncture headache was $66 \%$ in 1898 (7). High incidence was likely due to large bore needle, medium bevel and cutting spinal needle. Recent literature shows incidence of PDPH after intentional dural puncture varies from $0.1-36 \%$, the highest incidence of $36 \%$ was found after ambulatory diagnostic lumbar puncture using a 20-22 guage standard quincke spinal needle. (5) Reducing the size of the spinal needle has made direct impact on post spinal headache.

Relationship between needle size and incidence of postdural puncture headache

\begin{tabular}{|c|c|c|}
\hline Needle tip design & Needle gauge & $\begin{array}{l}\text { Incidence of post-dural } \\
\text { puncture headache (\%) }\end{array}$ \\
\hline Quincke & 22 & $36(10)$ \\
\hline Quincke & 25 & $3-25(11)$ \\
\hline Quincke & 26 & $0.3-20(12,13)$ \\
\hline Quincke & 27 & $1.5-5.6(14,15)$ \\
\hline Quincke & 29 & $0-2(11,12,15)$ \\
\hline Quincke & 32 & $0.4(18)$ \\
\hline Sprotte & 24 & $0-9.6(19,13)$ \\
\hline Whitacre & 20 & $2-5(20)$ \\
\hline Whitacre & 22 & $0.63-4(20,21)$ \\
\hline Whitacre & 25 & $0-14.5(19,22)$ \\
\hline Whitacre & 27 & $0(14)$ \\
\hline Atraucan & 26 & $2.5-4(23,24)$ \\
\hline Tuohy & 16 & $70(25)$ \\
\hline
\end{tabular}

The parturient is at higher risk of dural puncture and subsequent post spinal headache due their sex, age and widespread application of epidural anaesthesia.

\section{Materials and Method}

A prospective study was done on 100 patients to know the incidence of post dural puncture headache performed under spinal anaesthesia with 23G and 25G spinal needle undergoing lower segment caesarian section.

- The study was conducted at AVBRH attached to Jawaharlal Nehru Medical College between September 2015 to March 2016.

- Patients undergoing LSCS were randomly selected for the study.

- History was taken whether they had migraine, middle ear infection, received subarachnoid block earlier, how many pricks were taken, any experience of headache after receiving spinal anaesthesia previously.

- Daily follow up was done for a week and patients were asked if they experienced any kind of headache, nausea, vomiting.

A note was made about the timing of ambulation, NBM hours, breast feeding and urine output.

\section{Clinical presentation of PDPH: Severity}

0 - No headache.

1- Mild PDPH (VAS score 1-3) slight restriction of daily activities. Patient is not bedridden and no associated symptoms.

2 - Moderate PDPH (VAS score 4-7) significant restriction of daily activities. Patient is bedridden part of the day. Associated symptoms may or may not be present.

3 - Severe PDPH (VAS score 8-10) incapacitating headache, impossible to sit up. Associated symptoms were always present.

\section{Observation and Result}

- 3 out of 100 patients had complains of headache.

- Two had mild headache within 48hours which disappeared following administration of mild analgesic such as paracetamol orally.

- One had moderate headache with nausea and vomiting from the 1st post-operative day. In this case also, the $\mathrm{PDPH}$ and the associated symptoms disappeared by the 3rd day after treating the patient with mild analgesic and antiemetic (Ondansetron) this patient had H/o early ambulation.

- They were advised to increase fluid and caffeine intake and bed rest in supine position.

\section{Discussion}

Both biologic and psychosocial factors may contribute to the differences in pain perception, which may in part explain the increased incidence of reported PDPH in female subjects. Vasodilation of the cerebral vessels normally occurs in patients with $\mathrm{PDPH}$ as a homeostatic mechanism to compensate for cerebrospinal fluid loss and may contribute to the severity of PDPH. Estrogen is responsible to mediate cerebral artery tone and may dilate cerebral pial vessels younger (aged 30-40yr).

\section{Summery and Conclusion}

The incidence of postdural puncture headache is reduced greatly with the use of finer spinal needles, atraumatic needle and parallel direction of needle bevel in relation to dural fibers .

\section{References}

[1] Reid JA, Thorburn J. Headache after spinal anaesthesia. Br J Anaesth.1991; 67:674-7.

[2] Evans R W. Complications of lumbar puncture. Neurologic Clinics.Vol.16; no.1, 1998; 83-105.

[3] Dalessio DJ. Wolff's Headache and other Head pain.3rd Ed. New York; Oxford University Press, 1972; 22-31.

[4] Dr.U .Chouhan et al postdural puncture headache JPMA(Journal of Pakistan Medical Association) Vol:53,No.8 August 2003

[5] Kuntz KM, Kohmen E, Steven JC, et al. Post lumbar puncture headache: experience in 501 consectuve procedure. Neurology 1992;42:1884-7. 


\section{International Journal of Science and Research (IJSR) \\ ISSN (Online): 2319-7064 \\ Index Copernicus Value (2015): 78.96 | Impact Factor (2015): 6.391}

[6] Wulf HF. The centennial of spinal anesthesia. Anesthesiology 1998; 89: 500 \pm 6

[7] Hart JR, Whitacre RG. Pencil point needle in the prevention of post-spinal headache. JAMA 1951; 147: $657 \pm 8$

[8] Greene HM. Lumbar puncture and the prevention of post puncture headache. JAMA 1926; 86: 391 \pm 2

[9] Tourtellotte WW, Henderson WG, Tucker RP, Gilland O, Walker JE, Kokman E. A randomized, double-blind clinical trial comparing the 22 versus 26 gauge needle in the production of the post-lumbar puncture syndrome in normal individuals. Headache 1972; 12: 73 \pm 8

[10] Geurts JW, Haanschoten MC, van Wijk RM, Kraak H, Besse TC.Post-dural puncture headache in young patients. A comparative study between the use of 0.52 $\mathrm{mm}$ (25-gauge) and $0.33 \mathrm{~mm}$ (29-gauge) spinal needles. Acta Anaesthesiol Scand 1990; 34: 350 \pm 3

[11] Flaatten H, Rodt SA, Vamnes J, Rosland J, Wisborg T, Koller ME. Postdural puncture headache. A comparison between 26- and 29-gauge needles in young patients. Anaesthesia 1989; 44: 147 \pm 9

[12] Reynolds F, O`Sullivan G. Lumbar puncture and headache. 'Atraumatic needle' is a better term than 'blunt needle'. Br Med J 1998; 316: 1018

[13] Corbey MP, Bach AB, Lech K, Frorup AM. Grading of severity of postdural puncture headache after 27-gauge Quincke and Whitacre needles. Acta Anaesthesiol Scand 1997; 41: 779 \pm 84

[14] Kang SB, Goodnough DE, Lee YK, et al. Comparison of 26- and 27-G needles for spinal anesthesia for ambulatory surgery patients. Anesthesiology 1992; 76: $734 \pm 8$

[15] Sicard JA. Le Liquide Ceplalo - Rachdien. Paris, France : Massan et Gautier - Villars, 1902

[16] Moskowitz M. The trigemino-vascular system. In : Oleson J, Tflet-Hansen P, Welch K, (eds). The headaches. New York, NY: Raven, 1993, pp. 97-104

[17] Frumin MJ. Spinal anaesthesia using a 32-gauge needle. Anesthesiology 1969; 30: 599 \pm 60

[18] Campbell DC, Douglas MJ, Pavy TJ, Merrick P, Flanagan ML, McMorland GH. Comparison of the 25gauge Whitacre with the 24-gauge Sprotte spinal needle for elective Caesarean section: cost implications. Can J

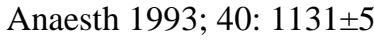

[19] Carrie LE. Whitacre and pencil-point needles: some points to consider. Anaesthesia 1990; 45: 1097 \pm 8

[20] Sears DH, Leeman MI, Jassy LJ, O`Donnell LA, Allen SG, Reisner LS. The frequency of postdural puncture headache in obstetric patients: a prospective study comparing the 24-gauge versus the 22-gauge Sprotte needle. J Clin Anesth 1994; 6: 42 \pm 6

[21] Quaynor H, Tronstad A, Heldaas O. Frequency and severity of headache after lumbar myelography using a 25-gauge pencil-point (Whitacre) spinal needle. Neuroradiology 1995; 37: 553 \pm 6

[22] Sharma SK, Gambling DR, Joshi GP, Sidawi JE, Herrera ER. Comparison of 26-gauge Atraucan and 25gauge Whitacre needles: insertion characteristics and complications. Can J Anaesth 1995; 42: 706 \pm 10

[23] Vallejo MC, Mandell GL, Sabo DP, Ramanathan S.Postduralpunctureheadache: a randomized comparison of ${ }^{\circledR}$ ve spinal needles in obstetric patients. Anesth Analg 2000; 91: 916 \pm 20
[24] Costigan SN, Sprigge JS. Dural puncture: the patients' perspective. A patient survey of cases at a DGH maternity unit $1983 \pm 1993$. Acta Anaesthesiol Scand 1996; 40: 710 \pm 14 puncture headache. JAMA 1926; 86: $391 \pm 2$ 